Supporting information for:

\title{
Dynamic Control of Photocatalytic Proton Reduction through Mechanical Actuation of a Hydrogel Host Matrix
}

Muwen Yang ${ }^{1}$, Qinsi Xiong ${ }^{1}$, Mohamad S. Kodaimati ${ }^{1}$, Xinyi Jiang ${ }^{1}$, Neil M. Schweitzer ${ }^{2}$, George C. Schatz ${ }^{1}$ and Emily A. Weiss ${ }^{1 *}$

${ }^{1}$ Department of Chemistry, Northwestern University, 2145 Sheridan Rd., Evanston, IL 60208-3113, United States.

${ }^{2}$ Department of Chemical and Biological Engineering, Northwestern University, 2145 Sheridan Rd., Evanston, IL 60208-3113, United States.

*corresponding author. Email: e-weiss@northwestern.edu

\section{SYNTHETIC PROCEDURES}

Synthesis of CdSe/CdS nanorods (NRs). NRs were synthesized using a procedure adapted from Amirav, L. and Alivisatos, A. P. ${ }^{1}$ First, we synthesized the CdSe seed. We degassed a mixture of $3.00 \mathrm{~g}$ of Trioctylphosphine oxide (TOPO), $0.280 \mathrm{~g}$ of Octadecylphosphonic acid (ODPA) and $60 \mathrm{mg}$ of cadmium oxide $(\mathrm{CdO})$ at $150^{\circ} \mathrm{C}$ under vacuum for $1 \mathrm{~h}$. Under $\mathrm{N}_{2}$ atmosphere, we raised the temperature to $270{ }^{\circ} \mathrm{C}$ and injected $1.8 \mathrm{~mL}$ trioctylphosphine (TOP) to the mixture. We then raised the temperature to $350{ }^{\circ} \mathrm{C}$ and rapidly injected $300 \mu \mathrm{L}$ of the TOP:Se solution, which was prepared by mixing $0.336 \mathrm{~g}$ Se with $2.5 \mathrm{~mL}$ TOP and stirring overnight in a $\mathrm{N}_{2}$ glovebox. We allowed the CdSe seeds to grow for $30 \mathrm{~s}$, and quenched the reaction by injecting $5 \mathrm{~mL}$ TOP and cooling down the mixture. After the synthesis, the CdSe seeds were precipitated with isopropanol and centrifuged. We then purified the pellet by dissolving it using hexane/toluene as solvent and then precipitating the $\mathrm{CdSe}$ seeds using isopropanol/acetone as non-solvent. We repeated this washing procedure three times.

To synthesize CdS NRs around the CdSe seeds, we mixed $3.00 \mathrm{~g}$ of TOPO, $0.280 \mathrm{~g}$ of ODPA, $0.060 \mathrm{~g}$ of $\mathrm{CdO}$ and $0.015 \mathrm{~g}$ of propylphosphonic acid (PPA) in a $50-\mathrm{mL}$ three-neck flask. The mixture was heated to $150{ }^{\circ} \mathrm{C}$ under vacuum for $1 \mathrm{~h}$, and then heated to $350{ }^{\circ} \mathrm{C}$ under flowing $\mathrm{N}_{2}$ until $\mathrm{CdO}$ fully dissolved and the solution turned transparent. To remove the water generated in this reaction, we cooled the mixture to $150^{\circ} \mathrm{C}$ and put it under vacuum for $1 \mathrm{~h}$. We then heated the mixture to $350{ }^{\circ} \mathrm{C}$ under $\mathrm{N}_{2}$, added $1.8 \mathrm{~mL}$ of TOP to the mixture, and, after the mixture returned to $350^{\circ} \mathrm{C}$, injected the seed solution, which was prepared by dissolving $30 \mathrm{nmol}$ of the dried CdSe seeds in the TOP:S solution (prepared by stirring a mixture of $1.8 \mathrm{~mL}$ TOP and $0.120 \mathrm{~g}$ S until all the $\mathrm{S}$ dissolved) in a glovebox. The reaction was allowed to react for 8 minutes and stopped by 
injection of $5 \mathrm{~mL}$ of TOP and removal of the heating mantle. Once cool, we added $4 \mathrm{~mL}$ of toluene to the reaction mixture and precipitated the NRs using a mixture of isopropanol and acetone. After centrifuging, the pellet was washed using two alternating cycles of (A) redissolution in toluene/hexane and precipitation using isopropanol/acetone, and (B) redissolution in toluene/hexane, addition of $2 \mathrm{~mL}$ of 1:1 nonanoic acid/octalamine and precipitation. We repeated the washing procedure three times. After washing, the NRs were dissolved and stored in hexanes.

Multiexciton studies showed that the threshold for the transition between quasi-type-II and type-I band alignment is at $2.75 \mathrm{~nm}^{2}{ }^{2}$ Other studies of core/shell photophysics ${ }^{3-5}$, quantumconfined stark effect ${ }^{6}$ and photocatalytic proton reduction ${ }^{1}$ however all indicate that the electrons in the NRs (core diameter $=2.9 \mathrm{~nm}$ ) are delocalized, and therefore that NRs have a quasi-type-II band alignment.

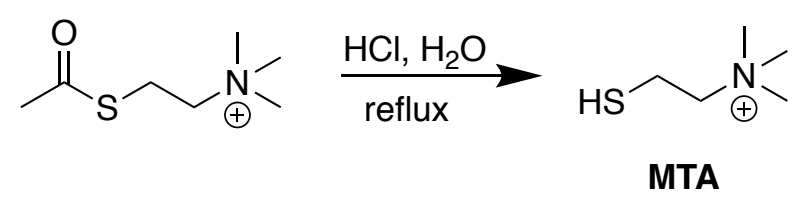

Synthesis of 2-Mercaptoethyl-N,N,N-trimethylammonium Chloride (MTA). The procedure was adapted from that of Bawendi, M. G. and co-workers. ${ }^{7}$ We dissolved acetylthiocholine chloride $(0.48 \mathrm{~g}, 2.6 \mathrm{mmol})$ in $1 \mathrm{M} \mathrm{HCl}(10 \mathrm{~mL})$ and refluxed the mixture at $110^{\circ}$ $\mathrm{C}$ under an inert atmosphere overnight. The product was purified using vacuum distillation and recrystallization with methanol, yielding white crystalline solids $\left(0.325 \mathrm{~g}, 82 \%\right.$ yield). ${ }^{1} \mathrm{H}$ NMR $\left(\mathrm{D}_{2} \mathrm{O}, 600 \mathrm{MHz}\right): \delta(\mathrm{ppm})=3.49-3.42(\mathrm{~m}, 2 \mathrm{H}), 3.07(\mathrm{~s}, 9 \mathrm{H}), 2.91-2.83(\mathrm{~m}, 2 \mathrm{H})$.<smiles>[R9][C@](C)(CC)NC(=C)C(=O)OCCOCCCl</smiles><smiles>C=C(C)C(=O)OCCOCCSC(C)=O</smiles>

Synthesis of 2-(2-acetylthioetoxy)ethyl methacrylate (AcSEOMA). The synthesis of AcSEOMA was adapted from the procedure published by García, O. et. al. ${ }^{8} \mathbf{1}$ was synthesized 
under flowing $\mathrm{N}_{2}$. Methacryloyl chloride $(9.7 \mathrm{~mL}, 0.088 \mathrm{~mol})$ was added dropwise at $0{ }^{\circ} \mathrm{C}$ to a solution of 2-(2-chloroethoxy)ethanol $(8.5 \mathrm{~mL}, 0.08 \mathrm{~mol})$ and triethylamine $(12.2 \mathrm{~mL}, 0.088 \mathrm{~mol})$ in $180 \mathrm{~mL}$ of anhydrous dichloromethane. The reaction was then allowed to reach room temperature and react overnight. The product was washed three times with $50 \mathrm{~mL}$ water and dried over anhydrous sodium sulfate (yellow liquid, $13.94 \mathrm{~g}, 75 \%$ yield). The product was used in the second step without purification. Then, a mixture of potassium thioacetate $(6.8 \mathrm{~g}, 0.059 \mathrm{~mol}), 2-$ (2-chloroetoxy)ethyl methacrylate $(11.1 \mathrm{~g}, 0.054 \mathrm{~mol})$ and potassium iodide (cat, $0.905 \mathrm{~g}, 0.005$ mol) were dissolved in $100 \mathrm{~mL}$ of acetone and refluxed at $60{ }^{\circ} \mathrm{C}$ for $12 \mathrm{~h}$. We filtered the product and removed the acetone, extracted the product with ethyl acetate, washed the solution with water and dried it over anhydrous sodium sulfate. The resulting dark liquid was purified using column chromatography using a gradient eluent of hexane/ethyl acetate with $0 \sim 35$ vol\% ethyl acetate. ${ }^{1} \mathrm{H}$ $\operatorname{NMR}\left(\mathrm{CDCl}_{3}, 600 \mathrm{MHz}\right): \delta(\mathrm{ppm})=6.16(\mathrm{dt}, J=1.7,1.0 \mathrm{~Hz}, 1 \mathrm{H}), 5.61(\mathrm{p}, J=1.6 \mathrm{~Hz}, 1 \mathrm{H}), 4.34$ $-4.28(\mathrm{~m}, 2 \mathrm{H}), 3.77-3.71(\mathrm{~m}, 2 \mathrm{H}), 3.65(\mathrm{t}, J=6.4 \mathrm{~Hz}, 2 \mathrm{H}), 3.11(\mathrm{t}, J=6.4 \mathrm{~Hz}, 2 \mathrm{H}), 2.36(\mathrm{~s}, 3 \mathrm{H})$, $1.98(\mathrm{~s}, 1 \mathrm{H})$.

Synthesis of 2-(2-sulfanylethoxy)ethyl 2-methylprop-2-enoate (SEOMA). The methanolysis of AcSEOMA was carried out by adding $20 \mu \mathrm{L}$ of AcSEOMA to a solution of $\mathrm{NaOMe}$ solution $(80 \mu \mathrm{L}$ of $25 \mathrm{wt} \% \mathrm{NaOMe}$ in methanol). The mixture was allowed to react overnight. The reaction was quenched with $1 \mathrm{~mL}$ of DI water, centrifuged and used directly for subsequent ligand exchange. ${ }^{1} \mathrm{H} \mathrm{NMR}\left(\mathrm{CDCl}_{3}, 600 \mathrm{MHz}\right): \delta(\mathrm{ppm})=6.17(\mathrm{dq}, J=2.0,1.0 \mathrm{~Hz}$, 1H), $5.62(\mathrm{p}, J=1.6 \mathrm{~Hz}, 1 \mathrm{H}), 4.36-4.29(\mathrm{~m}, 2 \mathrm{H}), 3.79-3.72(\mathrm{~m}, 2 \mathrm{H}), 3.66(\mathrm{t}, J=6.4 \mathrm{~Hz}, 2 \mathrm{H})$, $3.12(\mathrm{t}, J=6.4 \mathrm{~Hz}, 2 \mathrm{H}), 2.37(\mathrm{~s}, 3 \mathrm{H}), 1.99(\mathrm{dd}, J=1.6,1.0 \mathrm{~Hz}, 3 \mathrm{H})$.
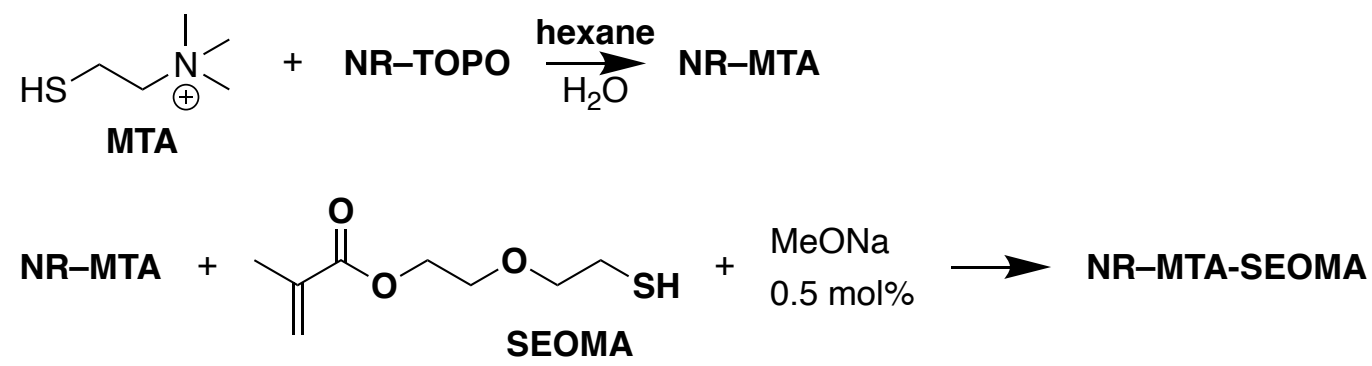

Ligand Exchange. We used adapted literature procedures for the MTA ligand exchange ${ }^{7}$ and the SEOMA ligand exchange. ${ }^{9}$

Ligand exchange with MTA. We dissolved MTA (56 mg, $360 \mu \mathrm{mol})$ in $1 \mathrm{~mL}$ water, tuned the $\mathrm{pH}$ to 6.0 , and added $30 \mathrm{nmol}$ of NRs in $3 \mathrm{~mL}$ of hexane to the MTA solution. We stirred the 
mixture vigorously for $\sim 1$ minute until the NRs were transferred from the organic phase to the aqueous phase. The MTA-capped NRs were precipitated using acetone/methanol, and the pellet was redissolved in $1 \mathrm{~mL}$ of DI water.

Ligand exchange with SEOMA. The supernatant of AcSEOMA after methanolysis was added to the $30 \mathrm{nmol}$ of NR-MTA solution and stirred vigorously for $1 \mathrm{~h}$. The ligand exchange was confirmed by the broadened peak at $\delta=3.0-2.5 \mathrm{ppm}$ (Figure S1). ${ }^{9}$

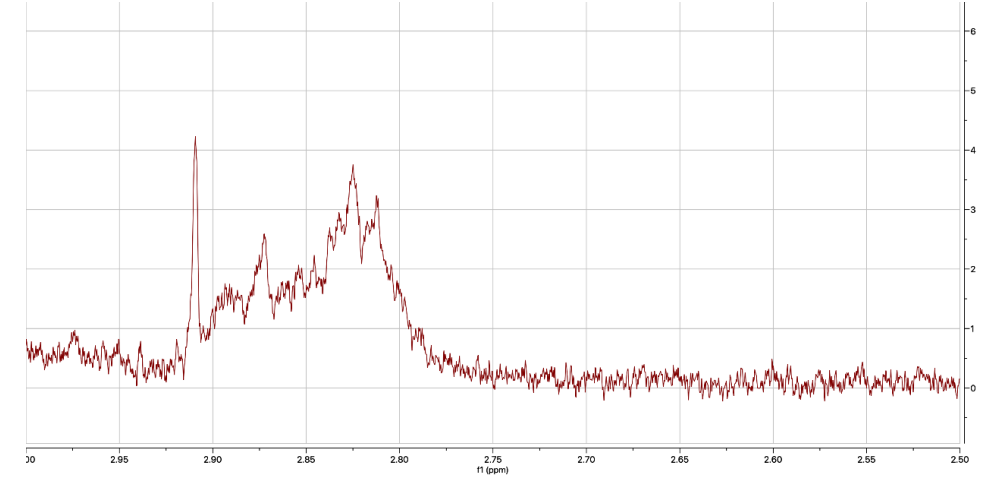

Figure S1. Zoomed ${ }^{1} \mathrm{H}$ NMR of NRs-MTA-SEOMA at $\delta=3.0-2.5 \mathrm{ppm}$. The broadened peak indicates that SEOMA was attached to the NRs surface.

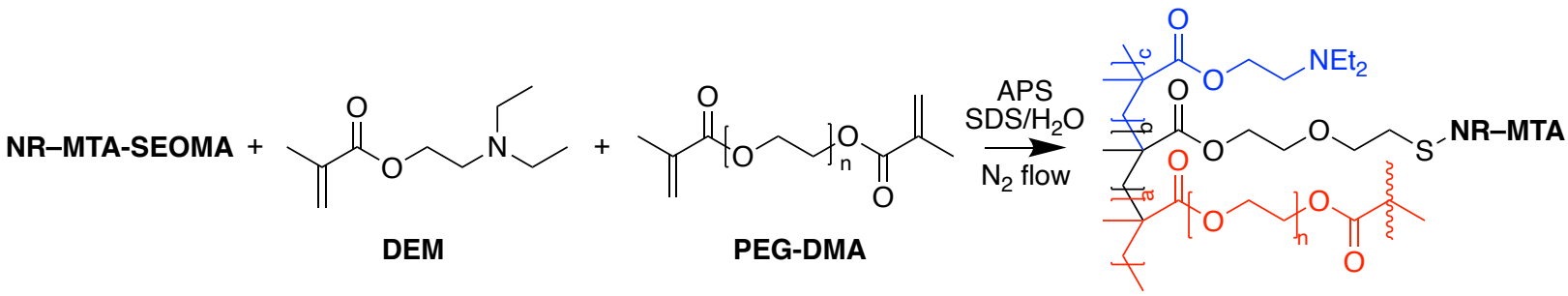

Synthesis of NR-Microgel Composites. To remove the inhibitors in 2-(diethylamino)ethyl methacrylate (DEM), we passed the monomer through a dry basic alumina column. A mixture of $1 \mathrm{~mL}$ of DEM, $10 \mu \mathrm{L}$ of poly(ethylene glycol) dimethacrylate (PEG-DMA, average $\mathrm{M}_{\mathrm{n}}=550$ ), and $5 \mathrm{~mL}$ of an aqueous solution of $4 \mathrm{mM}$ sodium dodecylsulfate (SDS) was degassed under a $\mathrm{N}_{2}$ atmosphere for 30 minutes in a three-neck flask. The NR-MTA-SEOMA solution and $1 \mathrm{~mL}$ of an aqueous solution of $40 \mathrm{mg} / \mathrm{mL}$ ammonium persulfate (APS) were degassed under flowing $\mathrm{N}_{2}$ separately for 30 minutes. The three-neck flask was heated to $70{ }^{\circ} \mathrm{C}$ after degassing, and the NRMTA-SEOMA solution was injected into the flask. After the temperature returned to $70{ }^{\circ} \mathrm{C}$, we added the APS solution and allowed the mixture to react at $70{ }^{\circ} \mathrm{C}$ for 6 hours under flowing $\mathrm{N}_{2}$. 
The product was purified with two cycles of centrifugation at $5000 \mathrm{rpm}$ for one minute and was resuspended in water.

Optical Spectra of NR-MTA-Microgel Composites. Ground-state absorption and PL spectra of NRs in hexane, NR-MTA and NR-microgel are shown in Figure S2. The sample was excited at $405 \mathrm{~nm}$ in the PL measurement and the PL intensities in the right panel were scaled by the sample absorptions at $405 \mathrm{~nm}$. The photoluminescence quantum yield decreases by a factor of 3.8 after the ligand exchange with MTA. The recovering of PL intensity after polymerization was observed in a similar material. ${ }^{9}$
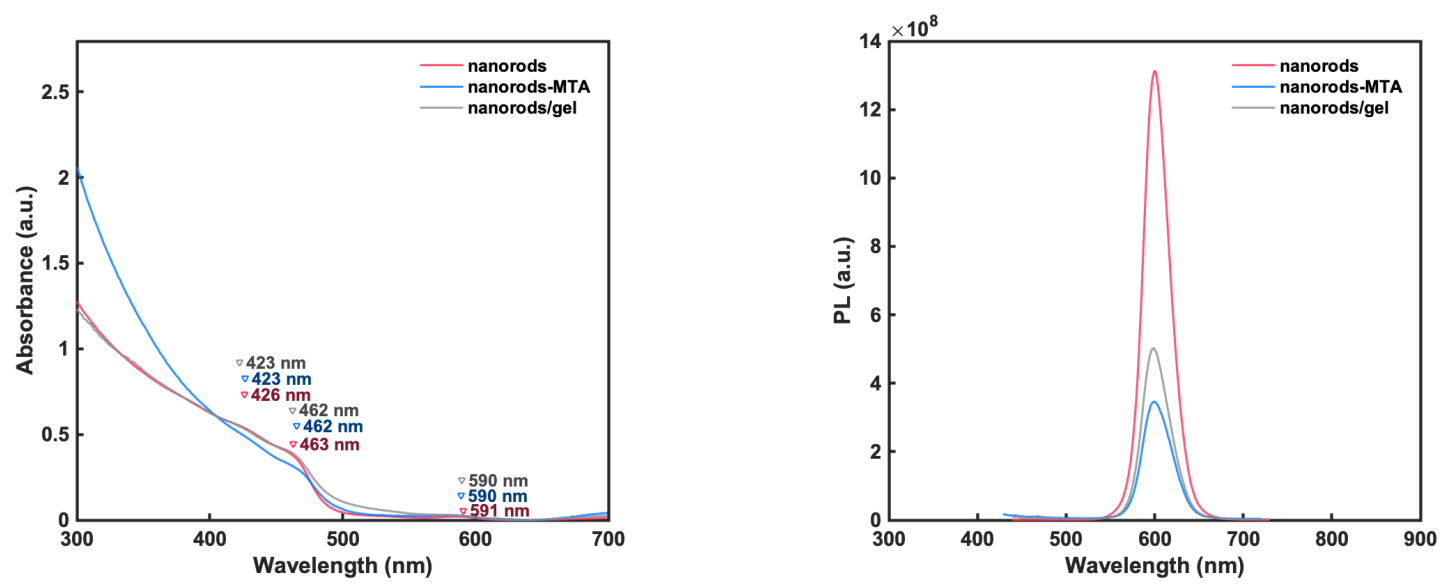

Figure S2. Absorption (left) and PL spectra (right) of NRs (red), NR-MTA (blue) and NRmicrogel (grey). The absorption peaks are labeled.

\section{CHARACTERIZATION PROCEDURES}

Ground State Absorption Spectroscopy. All ground state absorption spectra of NR and NRmicrogel samples were acquired on a Varian Cary 5000 spectrometer in a $2 \mathrm{~mm}$ quartz cuvette. All the spectra were baseline-corrected with a hexane (for NRs) or water (for NR-MTA, NRmicrogel) blank sample. We determined the size and concentrations of CdSe quantum dots and NRs from the position of the first excitonic peak using the calibration curve published by X. Peng et. al. ${ }^{10}$

Photoluminescence (PL) Spectroscopy. PL measurements were performed on a Horiba Fluorolog-3 spectrofluorometer using a right-angle geometry and a $2 \mathrm{~mm} / 10 \mathrm{~mm}$ quartz cuvette.

Nuclear Magnetic Resonance (NMR) Spectroscopy. ${ }^{1} \mathrm{H}$ NMR spectra were collected on a $500 \mathrm{MHz}$ Bruker Avance III HD system equipped with a TXO Prodigy probe. Chemical shifts for 
${ }^{1} \mathrm{H}$ spectra were referenced using internal solvent resonances and are reported relative to tetramethylsilane (TMS).

Transmission Electron Microscopy (TEM). Solutions of nanorods in hexane were dropcasted and dried on a carbon -coated grid. Scanning transmission electron microscopy images were collected on a JEOL JEM-2100 FasTEM operated at $200 \mathrm{kV}$.

Dynamic Light Scattering (DLS). DLS (Figure S3) was performed on the microgel samples with a dynamic light scattering analyzer (Malvern, Zetasizer Nano). The samples were contained in a 1-cm path-length cuvette and illuminated with a $633-\mathrm{nm}$ He-Ne laser at $25^{\circ} \mathrm{C}$. The $\mathrm{pH}$ of the solution was tuned using $0.05 \mathrm{M} \mathrm{NaOH}$ and $0.05 \mathrm{M} \mathrm{HCl}$. The $\mathrm{pH}$ of the microgel solution was measured before and after each DLS measurement.
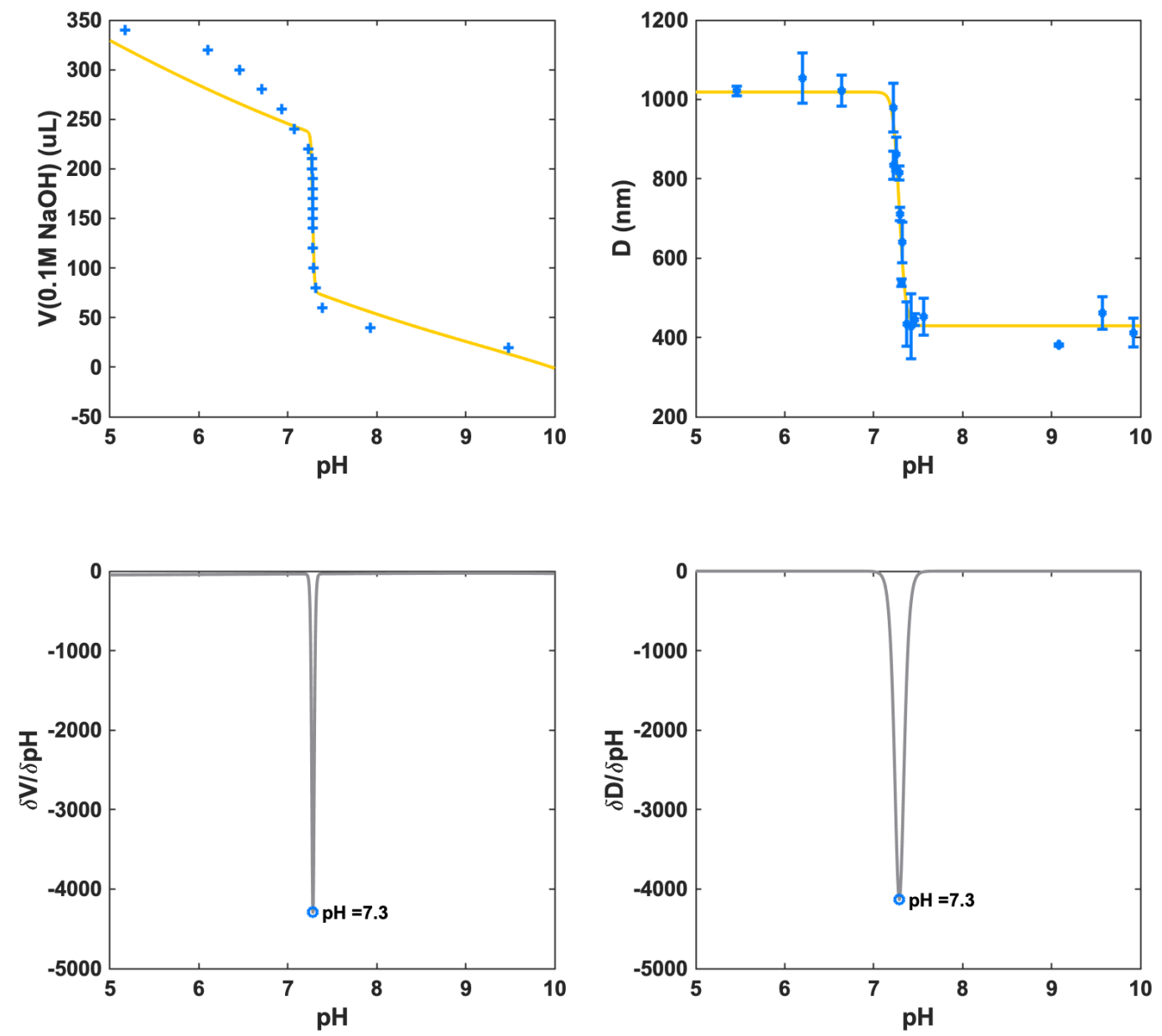

Figure S3. Full titration (left) and dynamic light scattering data (right) obtained at $\mathrm{pH}=5 \sim 10$. The $\mathrm{p} K_{a}$ was calculated by extracting the minimum in the first derivative plots (bottom). 


\section{Thermogravimetric Analysis-Gas Chromatography/Mass Spectroscopy (TGA-GC/MS).}

TGA-GC/MS experiments were performed in a Netzsch Jupiter F3 STA instrument coupled with GC-MS. The microgel sample was dried in a lyophilizer. About $30 \mathrm{mg}$ of the sample was transferred to an $\mathrm{Al}_{2} \mathrm{O}_{3}$ crucible, weighed on a microbalance $(1 \mathrm{ug})$. About $10 \mathrm{mg}$ of DI water was added to the dry microgel. The mixture was weighed and fully mixed.

After loading the sample crucible, the furnace was held at $37^{\circ} \mathrm{C}$ for 10 minutes under ultrahigh purity He gas (40 mL/min). Buoyancy effect for Helium air was corrected by measuring the empty crucible under the same measurement conditions used for the samples. Then, the temperature was increased from $37^{\circ} \mathrm{C}$ to $60^{\circ} \mathrm{C}$ at a rate of $1{ }^{\circ} \mathrm{C} / \mathrm{min}$ and held at $60^{\circ} \mathrm{C}$ for 4 hours (when the GC detection was turned on). After that, we raised the temperature at $1{ }^{\circ} \mathrm{C} / \mathrm{min}$ from $60{ }^{\circ} \mathrm{C}$ to $200{ }^{\circ} \mathrm{C}$. The sample was then cooled down to $30^{\circ} \mathrm{C}$ at a rate of $15^{\circ} \mathrm{C} / \mathrm{min}$ and stabilized at $30^{\circ} \mathrm{C}$ for another 20 minutes.

Gases were transferred to the GC/MS instrumentation via a heated $\left(250{ }^{\circ} \mathrm{C}\right)$ transfer line. An Agilent Technologies 7890A GC system equipped with a non-polar capillary column (Agilent J\&B HP-5 packed with (5\%-Phenyl)-methylpolysiloxane) coupled with a 5975 MSD spectrometer was used for the analyses of the gases released from the samples. A gas injection was triggered every 0.5 minutes from the beginning of the heating cycle and $0.25 \mathrm{ml}$ of gas was sampled from the gases released by the compound and carrier gas (Helium). The sample was injected every 1 minute into the GC column.

We also measured a control sample of $30 \mathrm{mg}$ dry microgel, without added water. To quantify the amount of water, we performed calibration using $0 \sim 0.6 \mathrm{mg}$ certified sample of calcium oxalate monohydrate (European Pharmacopoeia Reference Standard).

In a representative TGA-GC/MS plot (Figure S4), the free water, bound water and water generated from the degradation of the microgel corresponds to the MS peaks before $100 \mathrm{~min}$ $\left(60{ }^{\circ} \mathrm{C}\right), 240 \sim 330 \mathrm{~min}\left(60 \sim 240{ }^{\circ} \mathrm{C}\right)$ and after $330 \min \left(>240{ }^{\circ} \mathrm{C}\right)$. The calculated ratio of the bound water mass in microgels in their swelled and contracted states is 1.9. 


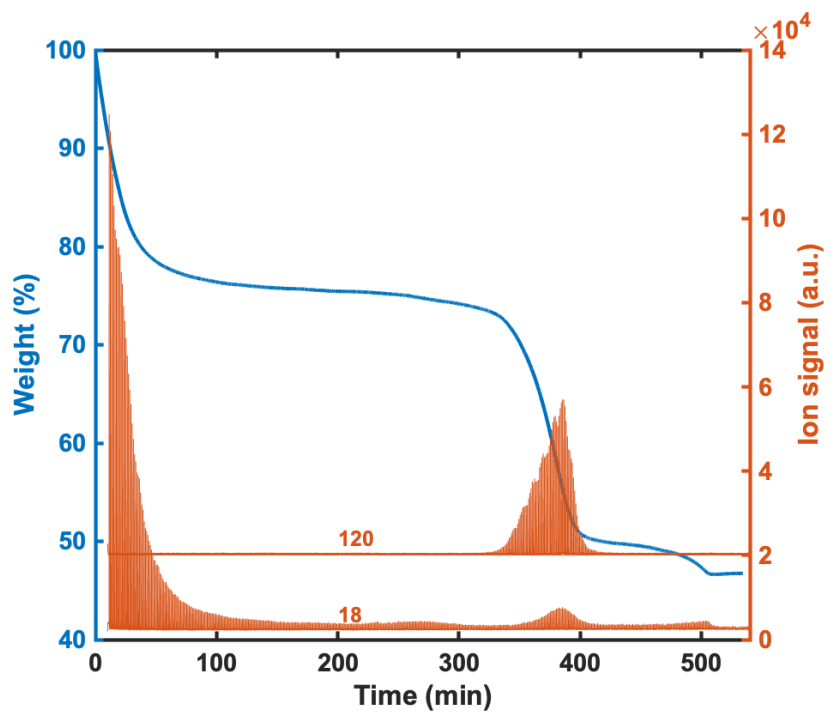

Figure S4. Representative TGA-GC/MS plot.

Gel Permeation Chromatography (GPC). Gel permeation chromatography (GPC) was performed on a Waters Breeze system equipped with two Waters Styragel HR 4E columns and one Styragel HR 5 column and a Waters 2414 refractive index detector. 0.01M lithium bromide (ACS grade, Sigma-Aldrich) solution in N,N-dimethylformamide (HPLC grade, Fisher Scientific) was used as the eluent with the column temperature at $80 \mathrm{oC}$ and the flow rate at $1 \mathrm{~mL} / \mathrm{min}$. A set of poly(methyl methacrylate) standard samples (ReadyCal, Sigma-Aldrich) were used to generate a calibration curve for the molar mass. The results are discussed in the main text and the GPC trace is shown in Figure S5.
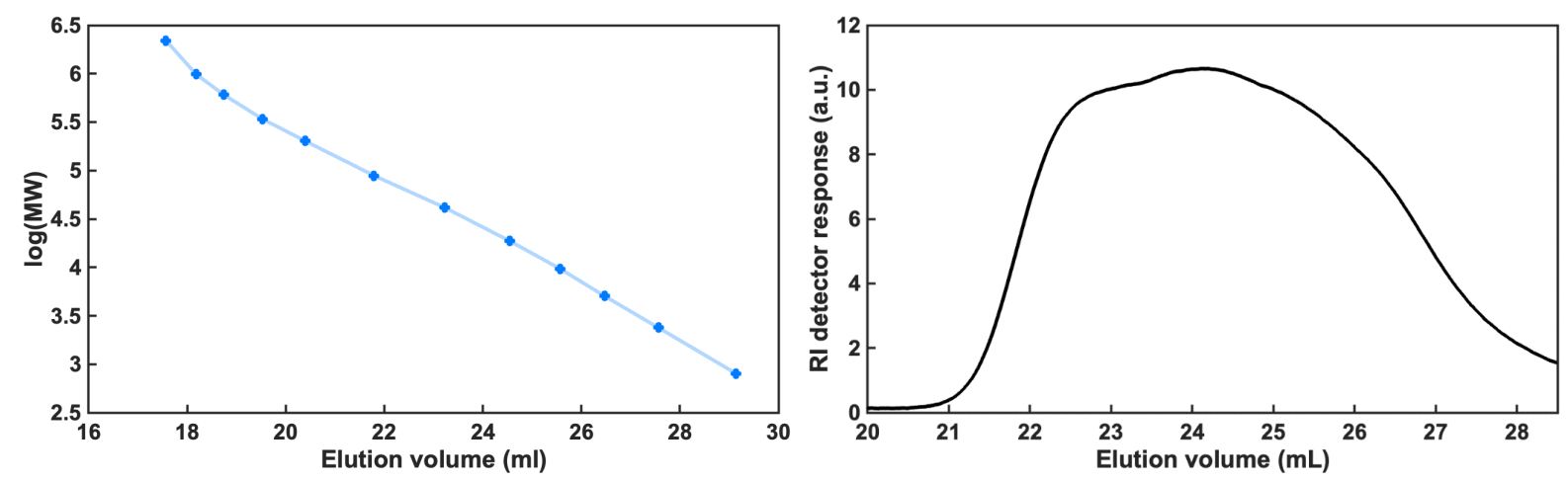

Figure S5. GPC calibration plot (top) and GPC traces of the DEM microgels in DMF with 0.01M $\mathrm{LiBr}$ (bottom). The average molecular weight is $13 \mathrm{kDa}$, and the PDI is 2.4. 
Characterization of the crosslinker contents in the microgel. We determined the molar ratio of the DEM motif to the PEG-DMA crosslinker in the microgel using their characteristic NMR peaks, following a literature procedure. ${ }^{11}$ The NMR peaks at $\delta=3.93 \mathrm{ppm}$ and $\delta=3.65 \mathrm{ppm}$ correspond to oxymethylene protons adjacent to the ester group of the DMA residues (2H) and oxyethylene protons on the PEG-DMA crosslinker $(36 \mathrm{H})$. The ratio of the area of these two peaks is $49.27: 1$, and the molar ratio of DEM to PEG-DMA in the microgel is $887: 1$.

Confocal Microscopy. Confocal microscopy was carried out on a Leica TCS SP8 LSCM instrument using a 20x multi-immersion objective (HC PL APO 20x/0.75 IMM CS2, Leica). The sample was excited with a $405 \mathrm{~nm}$ laser, and the PL emission was detected by HyD detector from 580 to $620 \mathrm{~nm}$. The distribution of NRs in the microgel is shown in Figure S6, which is a $30 \times 30$ $\mu \mathrm{m}$ confocal image with $1024 \times 1024$ pixels $(\sim 30 \mathrm{~nm} /$ pixel $)$. Given the $405 \mathrm{~nm}$ excitation wavelength, the resolution of this confocal map is diffraction-limited. The PL intensity is homogeneous throughout the microgel. Figures S6-S8 show additional confocal microscopy images.

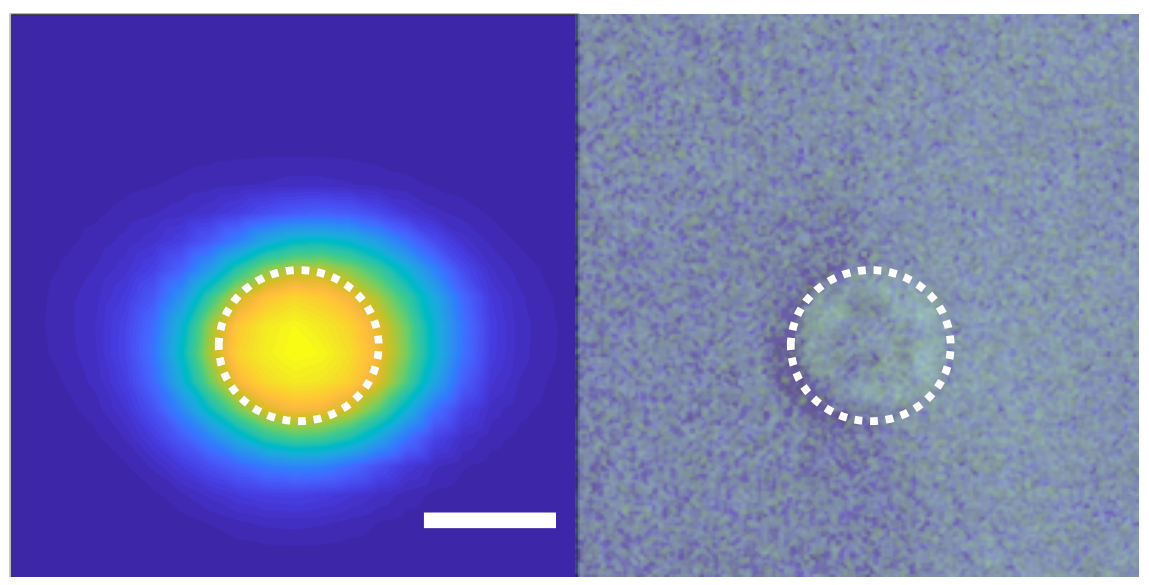

Figure S6. Confocal fluorescent map (left) and bright field image (right) of the microgel (scale bar, $5 \mu \mathrm{m})$. The white dashed line marks the edge of the microgel. 

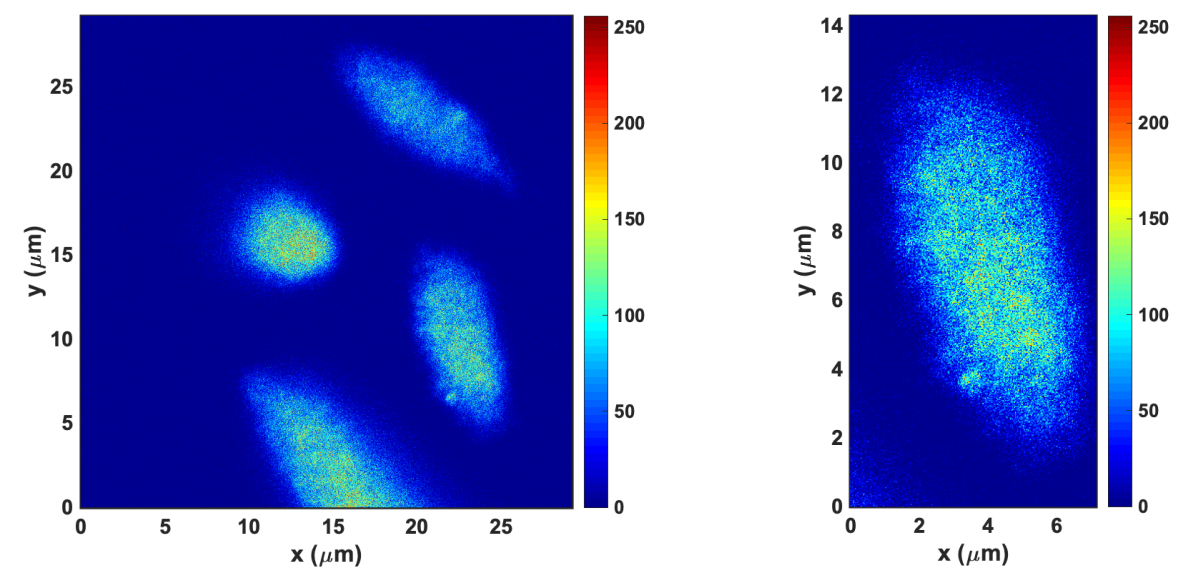

Figure S7. Additional confocal fluorescent maps. Left: $30 \times 30 \mu \mathrm{m}$ confocal fluorescent map acquired with $1024 \times 1024$ pixels. Right: A zoomed image of one of the microgels with diffractionlimited PL from single particles/clusters of NRs.
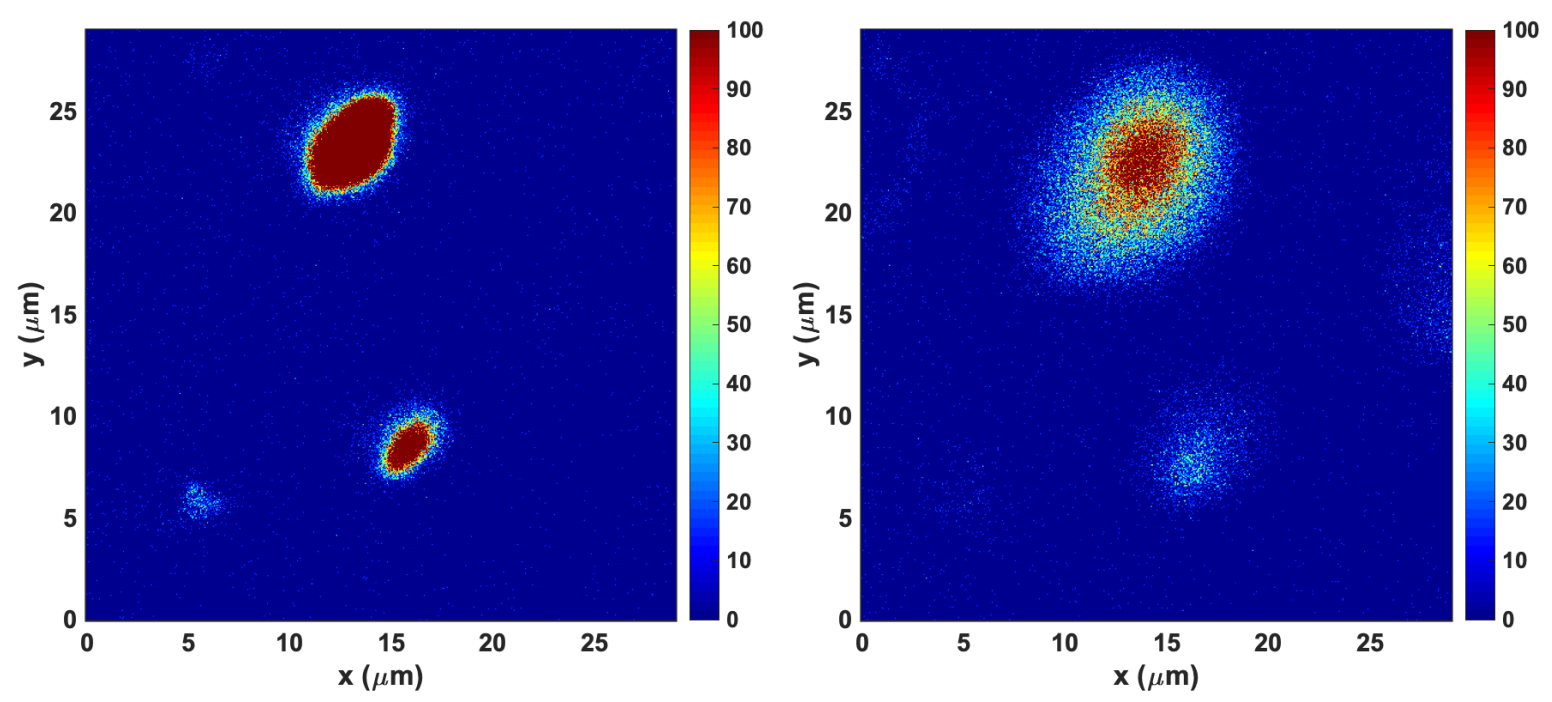

Figure S8. Two frames from a video of the NRs-microgel composite before (left, $\mathrm{pH}=9.7)$ and $0.58 \mathrm{~s}$ (right) after injecting $\mathrm{pH}=4.7,0.1 \mathrm{M}$ phosphate solution. We did not observe further swelling after taking the frame on the right. The sizes of the confocal fluorescent maps are $29.0 \times$ $29.0 \mu \mathrm{m}(512 \times 512$ pixels $)$. 

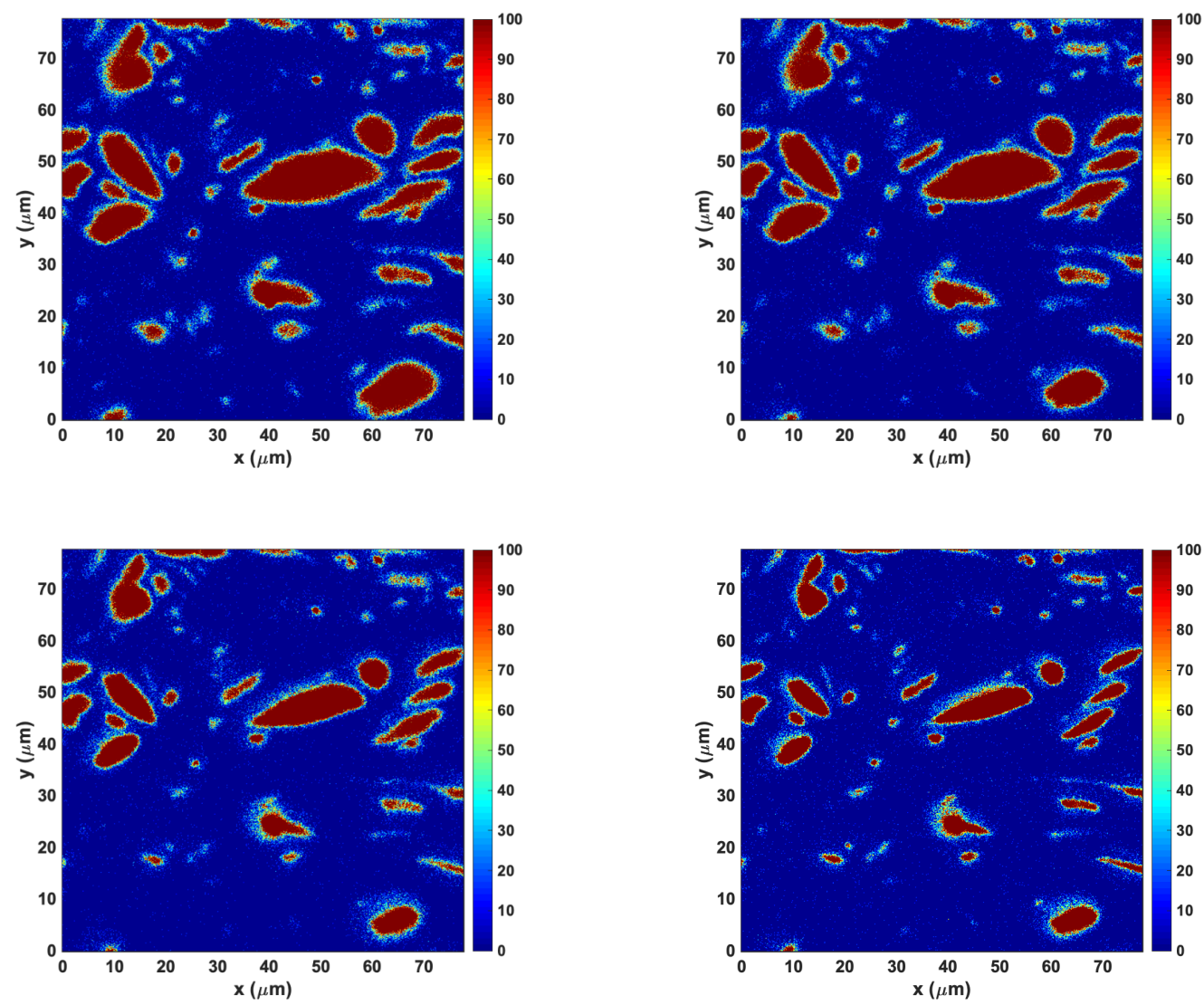

Figure S9. Four frames from a video of the NRs-microgel composite before (top left, $\mathrm{pH}=4.7$ ) and $0.58 \mathrm{~s}$ (top right), $1.16 \mathrm{~s}$ (bottom left), $1.74 \mathrm{~s}$ (bottom right) after injecting $\mathrm{pH}=9.7,0.1 \mathrm{M}$ phosphate solution. We did not observe further contraction after taking the frame on the right. The confocal fluorescent maps are $77.6 \times 77.6 \mu \mathrm{m}(512 \times 512$ pixels $)$.

Photocatalysis. Photocatalysis experiments were carried out in a home-built photocatalysis cell connected to an Agilent 7890A GC system equipped with a thermal conductivity detector (Figure S10) and a molecular sieve packed column (Agilent J\&W GC HP-PLOT Molesieve GC Column). The reactor was illuminated with two $15-\mathrm{mW}$ laser pointers at $405 \mathrm{~nm}$, except in the power-dependence experiment in which we used three 15-mW laser pointers (Figure S13).

The NR-microgel composite was diluted to $\mathrm{OD}=0.5$ at $405 \mathrm{~nm}(2 \mathrm{~mm}$ cuvette $)$ in an aqueous buffer of sodium sulfite. The concentration of nanorods is calculated to be $0.61 \mu \mathrm{M}$ using the empirical relationship between the absorptivity of the first excitonic peak and the concentration for this particular material. ${ }^{10}$ The total quantity of nanorods is then $0.61 \mu \mathrm{M} * 3.5 \mathrm{~mL}=2.1 \mathrm{nmol}$. After dilution, the concentration of the $\mathrm{Na}_{2} \mathrm{SO}_{3}$ was $0.1 \mathrm{M}$ and the $\mathrm{pH}$ was tuned to the desired $\mathrm{pH}$ 
values. We used $3.5 \mathrm{~mL}$ of the $\mathrm{NR}-$ microgel $/ \mathrm{Na}_{2} \mathrm{SO}_{3}$ solution for each photocatalysis experiment. For the control experiment, we diluted NRs and microgel solutions in a sodium sulfite buffer. The added microgels were diluted such that the scattering background at $\mathrm{pH}=8$ equals that in the experiment group at the same $\mathrm{pH}$. We measured the $\mathrm{pH}$ of the solution before and after the reaction and used this range as the horizontal error bar in Figures 2a-b.

Before each measurement, the reactor was purged with $\mathrm{N}_{2}$ at $150 \mathrm{sccm}$ for 20 minutes. Once completed, the purging was confirmed using GC. During the reaction, we closed the six-way valve effectively bypassing the purging gas so that the gas in the reactor is trapped (Figure S10). The gas was circulated in the reaction vial by manually pumping the system using a syringe.

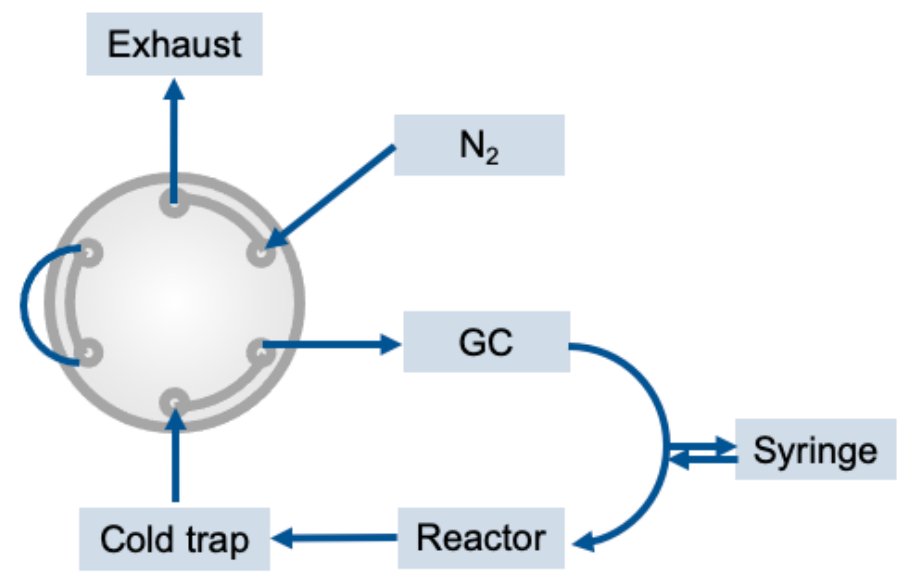

Figure S10. Schematic of the photocatalysis setup.

The accumulated $\mathrm{H}_{2}$ was quantified through periodic headspace gas analysis by $\mathrm{GC}$. The amount of generated $\mathrm{H}_{2}$ was calibrated using a mixture of $1000 \mathrm{ppm} \mathrm{H}_{2} / \mathrm{N}_{2}$ and pure $\mathrm{N}_{2}$. We fixed the flow rate of $\mathrm{N}_{2}$ to be $150 \mathrm{sccm}$ and varied the flow rate of the $1000 \mathrm{ppm} \mathrm{H}_{2} / \mathrm{N}_{2}$ gas mixture from 0 to $35 \mathrm{sccm}$ at $5 \mathrm{sccm}$ intervals. The concentration of $\mathrm{H}_{2}$ in the mixed gas ranges from 0 to $\frac{35}{35+150} * 1000 \mathrm{ppm}=189 \mathrm{ppm}$. The pressure of the gas mixture was $1.3 \mathrm{~atm}$. We calculated the amount of $\mathrm{H}_{2}$ injected using the gas law, assuming ideal gas, and obtained the following calibration curve for $\mathrm{H}_{2}$ (Figure $\mathrm{S} 11$ ). 


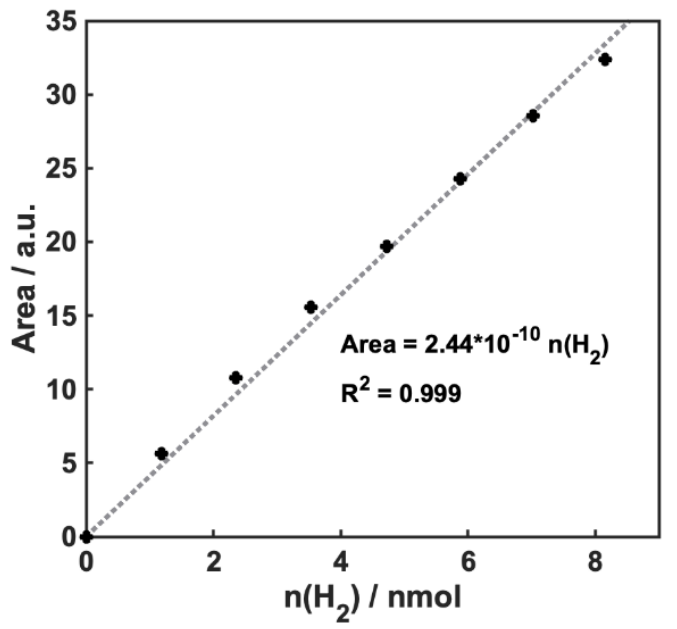

Figure S11. GC Calibration curve at $\mathrm{n}\left(\mathrm{H}_{2}\right)<10$ nmol.

We performed least squares linear fits to the kinetic traces (with at least 5 points in each kinetic trace) and the standard deviations of all kinetic traces are above 0.95 (Figure S12).
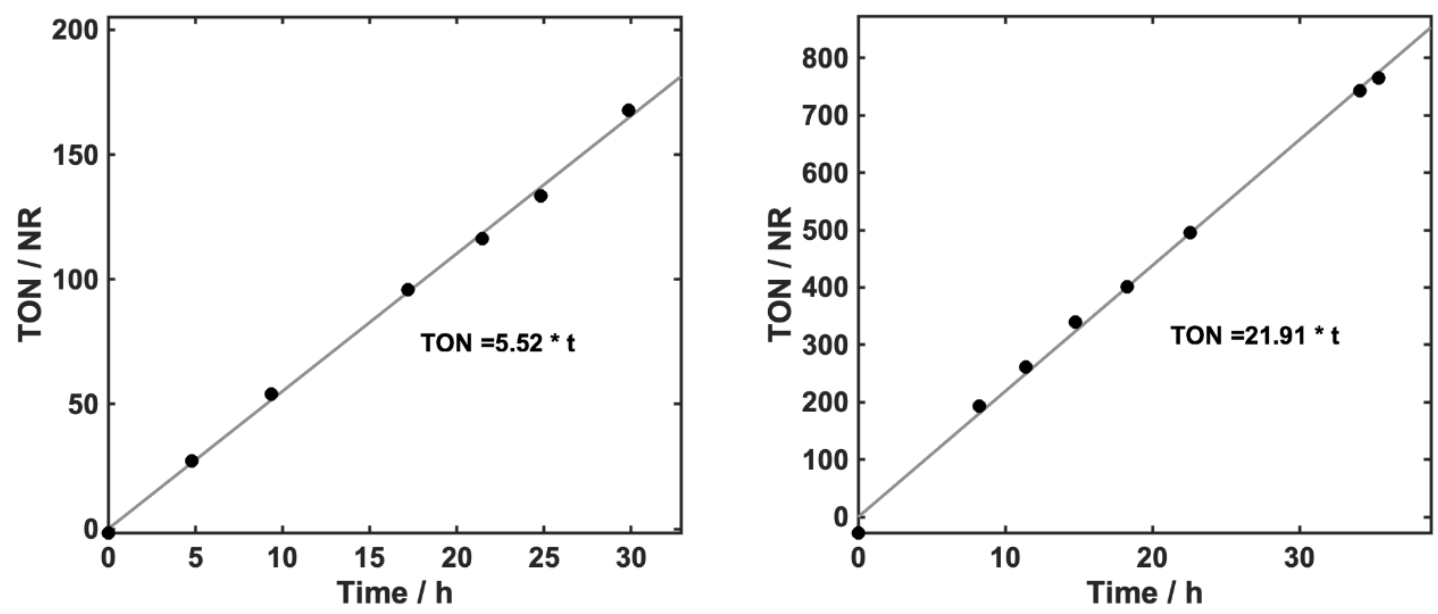

Figure S12. The kinetic traces for the photocatalytic proton reduction of the NR-microgel composite at $\mathrm{pH}=7.36$ (left) and $\mathrm{pH}=7.01$ (right). The y axis corresponds to the turnover number (TON) for each NR.

We performed an empirical linear fit to the TOF $v s . \mathrm{pH}$ plot of the control group (mixture of NR and microgels) and then divided the TOF of the experiment group (NR-microgel composite) by the linearly extrapolated TOF of the control group to obtain the TOF ratio shown in Figure $2 b$. 


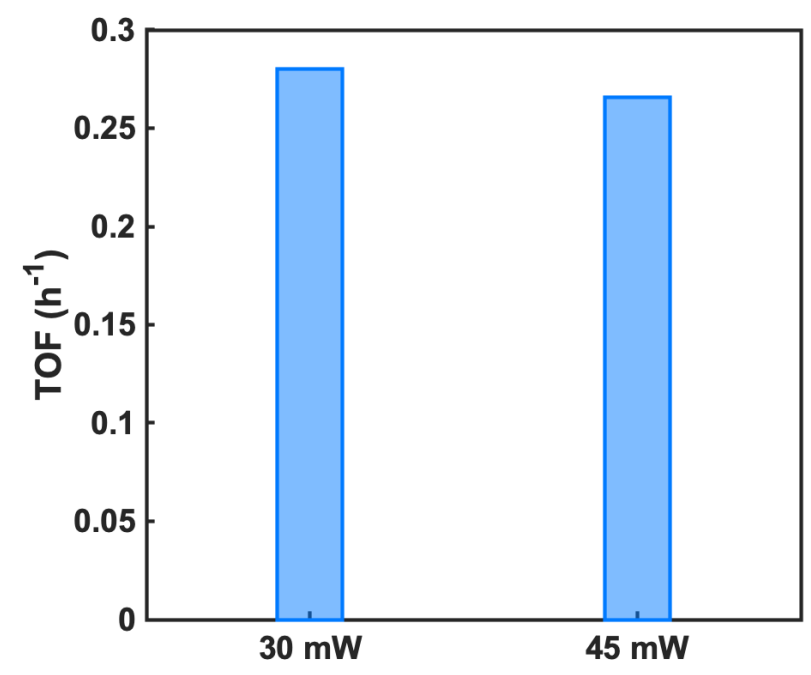

Figure S13. The TOF of proton reduction in the photocatalysis experiment using an illumination power of $30 \mathrm{~mW}$ and $45 \mathrm{~mW}$.

In the kinetic isotope effect experiments, we substituted $\mathrm{H}_{2} \mathrm{O}$ with $\mathrm{D}_{2} \mathrm{O}$ and measured the turnover frequency (TOF) for the photocatalytic proton reduction under the same conditions. We observed that the photocatalytic TOF of the deuterated samples decreased by $3.9 \%$ and increased by $0.5 \%$ at $\mathrm{pH}<\mathrm{p} K_{a}$ and $\mathrm{pH}>\mathrm{p} K_{a}$, respectively, compared with the non-deuterated samples. Going from swelled to contracted NR-microgel, the TOF of the deuterated sample changes by a factor of 4.8 .

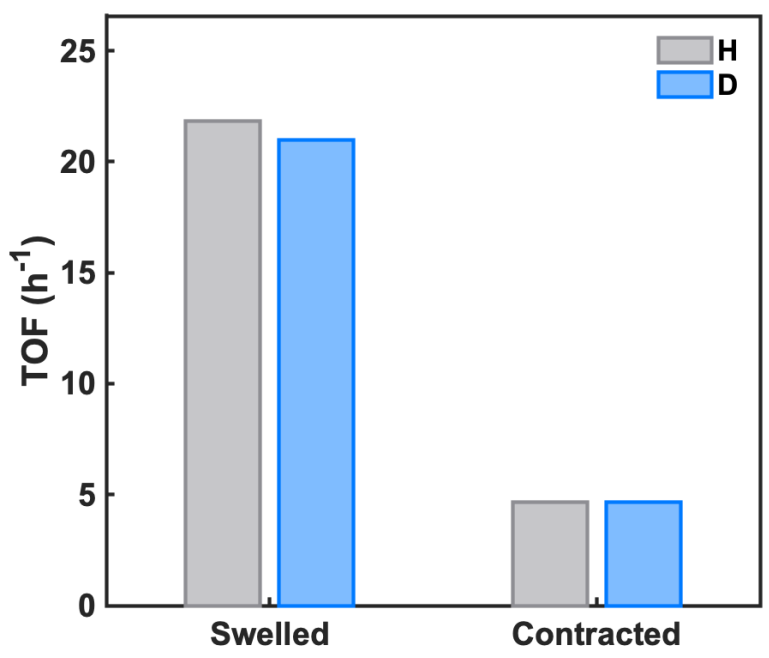

Figure S14. The TOF of proton reduction in the photocatalysis experiment using H (grey) vs D (blue). 
Stern-Volmer Analysis. We prepared $\mathrm{Na}_{2} \mathrm{SO}_{3}$ buffers at $\mathrm{pH}=7.1$ and $\mathrm{pH}=7.4$. An aqueous solution of NR-MTA was diluted with the $\mathrm{Na}_{2} \mathrm{SO}_{3}$ buffers, and the $\mathrm{pH}$ was measured and tuned to the desired $\mathrm{pH}(\mathrm{pH}=7.1$ for the swelled state and $\mathrm{pH}=7.4$ for the contracted state). Each sample containing NR-MTA and $\mathrm{Na}_{2} \mathrm{SO}_{3}$ buffers was degassed with freeze-pump-thaw cycling and stored in a $\mathrm{N}_{2}$ box overnight to equilibrate. The PL emission spectra were measured using $405 \mathrm{~nm}$ excitation, and the integrated PL was normalized by the absorption at $405 \mathrm{~nm}$ after background subtraction.

Molecular Dynamics Simulations. We parameterized the deprotonated and protonated DEM molecules using the general AMBER force field (GAFF). ${ }^{12}$ We performed geometry optimization of the deprotonated and protonated DEM molecules using density functional theory (DFT) at the B3LYP/6-311G** level using the ORCA software ${ }^{13}$, and generated the initial molecular geometries from these optimized structures. We derived the partial charges on the molecules from RESP2 with $\delta=0.5$ (restrained electrostatic potential ${ }^{14}$ ), which uses a two-stage fitting protocol implemented in Multiwfn software ${ }^{15}$. We used the Lennard-Jones parameters for sulfite ion derived from $a b$ initio calculations. ${ }^{16}$

In the simulation box $\left(90 \AA \times 90 \AA \times 90 \AA\right.$ ) with $0.1 \mathrm{M} \mathrm{Na}_{2} \mathrm{SO}_{3}$, we randomly dispersed 20 polymer chains, each of which contains 20 monomers (Figure S15). We added chloride anions as counter ions to neutralize the additional charges caused by a varied degrees of protonation. The addition of chloride ions to the simulations box is consistent with the experiment in which we added $\mathrm{HCl}$ to tune the $\mathrm{pH}$. We used the TIP4P water model. We simulated 7 different protonation levels, from $0 \%$ to $100 \%$ protonation with an interval of $20 \%$ and $50 \%$ protonation. We varied the level of protonation of the amine group on the DEM monomers to simulate different $\mathrm{pH}$ values of the solution. We realize that $100 \%$ protonation isn't possible because of charge regulation (coupled acid/base equilibrium) effects, however, it is only the qualitative trends that we are studying so this issue will be ignored.

All simulations in this study were conducted using the GROMACS 2018.1 package ${ }^{17-18}$. All the systems were subject to a 5000-steps energy minimization followed by a 500 ps simulation conducted at $298 \mathrm{~K}$ with the V-rescale thermostat. Polymers were positionally restrained during the energy minimization. After that, we slowly removed the constraints and conducted another 1 ns simulation at $298 \mathrm{~K}$ to further relax the system. The particle mesh Ewald method ${ }^{19}$ was employed to calculate electrostatic interactions with a short-range cutoff of $1.2 \mathrm{~nm}$. The boundary 
conditions were periodic in all three directions, and the simulation time step was $1 \mathrm{fs}$. Next, we performed SAMD (simulated annealing molecular simulations) for $100 \mathrm{~ns}$ at $310 \mathrm{~K} \sim 370 \mathrm{~K}$ and $1.0 \mathrm{~atm}$. The V-rescale method and the Parrinello-Rahman method were used to maintain the simulation temperature and pressure, respectively. In SAMD simulations, the systems were heated and annealed repeatedly for 3 cycles. In each cycle, the simulations started at the highest temperature $(370 \mathrm{~K})$ for $500 \mathrm{ps}$, and then we lowered the temperature at a rate of $2 \mathrm{~K} / \mathrm{ns}$. After these annealing cycles, the temperature was held at $310 \mathrm{~K}$ for another $20 \mathrm{~ns}$.
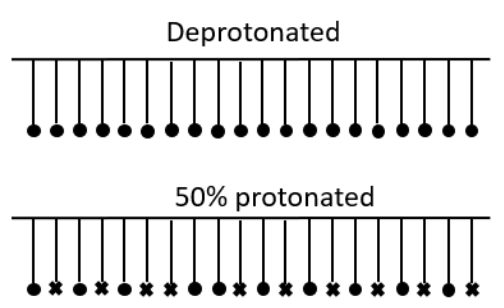
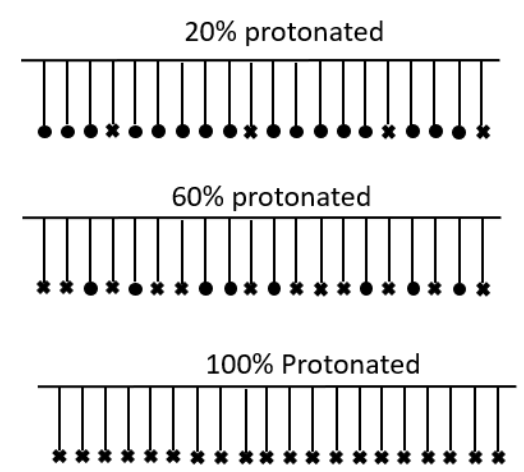
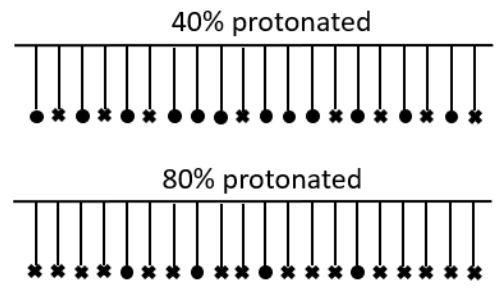

Figure S15. Representation of DEM polymers with different protonation levels. represents a deprotonated amine group and " $\mathrm{X}$ " represents a protonated amine group.

When going from a fully deprotonated to a fully protonated microgel there is a significant increase in the $\mathrm{N}$-water radial distribution function (RDF) at radii up to $20 \AA$ (Figure S17). Specifically, the peak in the RDF plot at $4.65 \AA$ increases from 0.55 to 0.99 , and the coordination number (integration of RDF from 0 to $4.65 \AA$ ) increases from 10.4 to 19.8 , consistent with the 1.9fold increase in the amount of bound water we measured by thermogravimetric analysis (Figure S4). The electrostatic interaction between sulfite anions and the protonated amine groups on the microgel leads to the depletion of water molecules in its first coordination sphere, causing the coordination number (integration of RDF from 0 to $2.25 \AA$ ) to decrease from 0.20 to 0 (Figures S16-S17). 

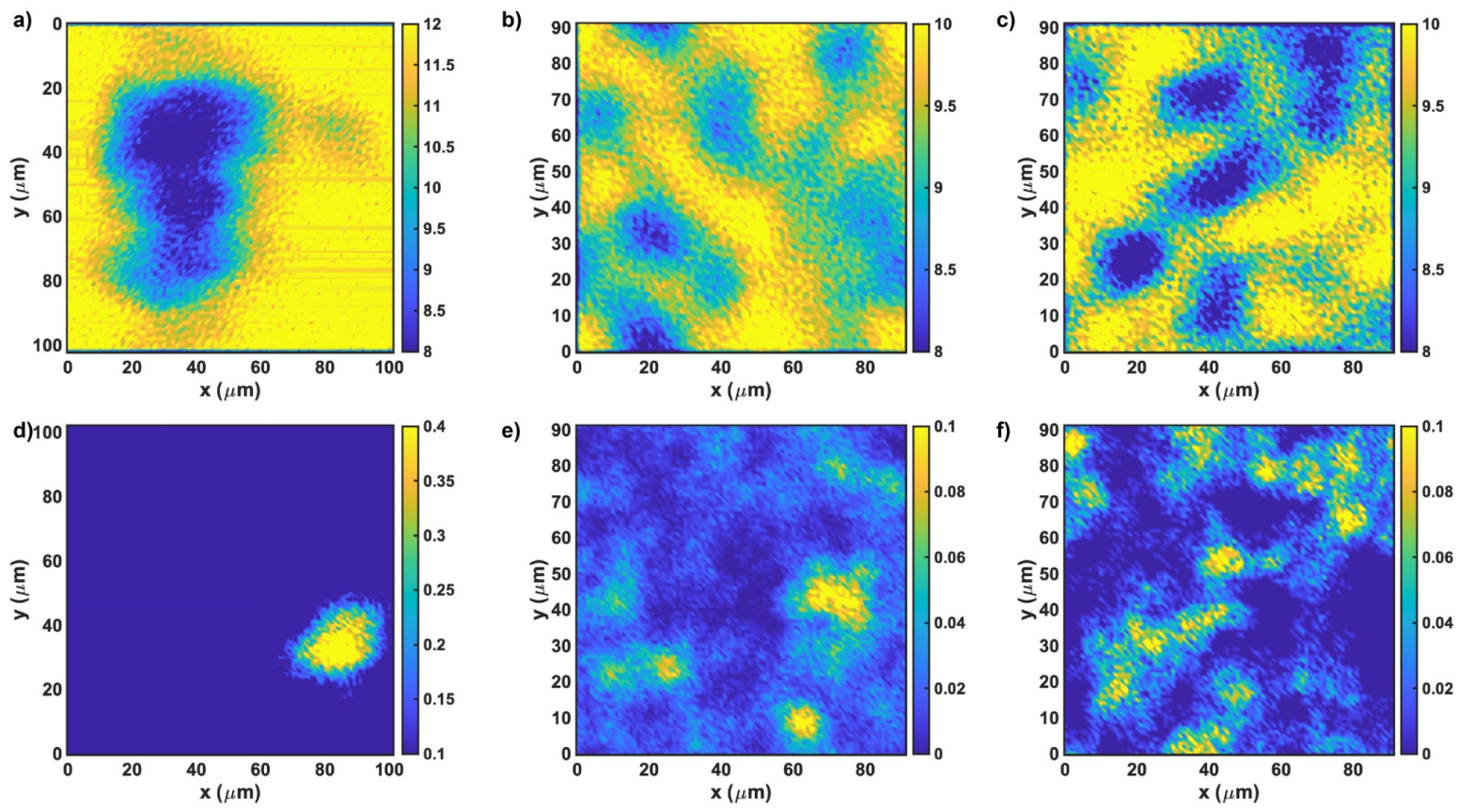

Figure S16. The 2D spatial distribution of water (a-c) and sulfite (d-f) number density averaged over the $z$ axis during the last $10 \mathrm{~ns}$ of simulation time for the microgel at $0 \%(\mathbf{a}, \mathbf{d}), 50 \%(\mathbf{b}, \mathbf{e})$ and $100 \%$ (c, f) levels of protonation.
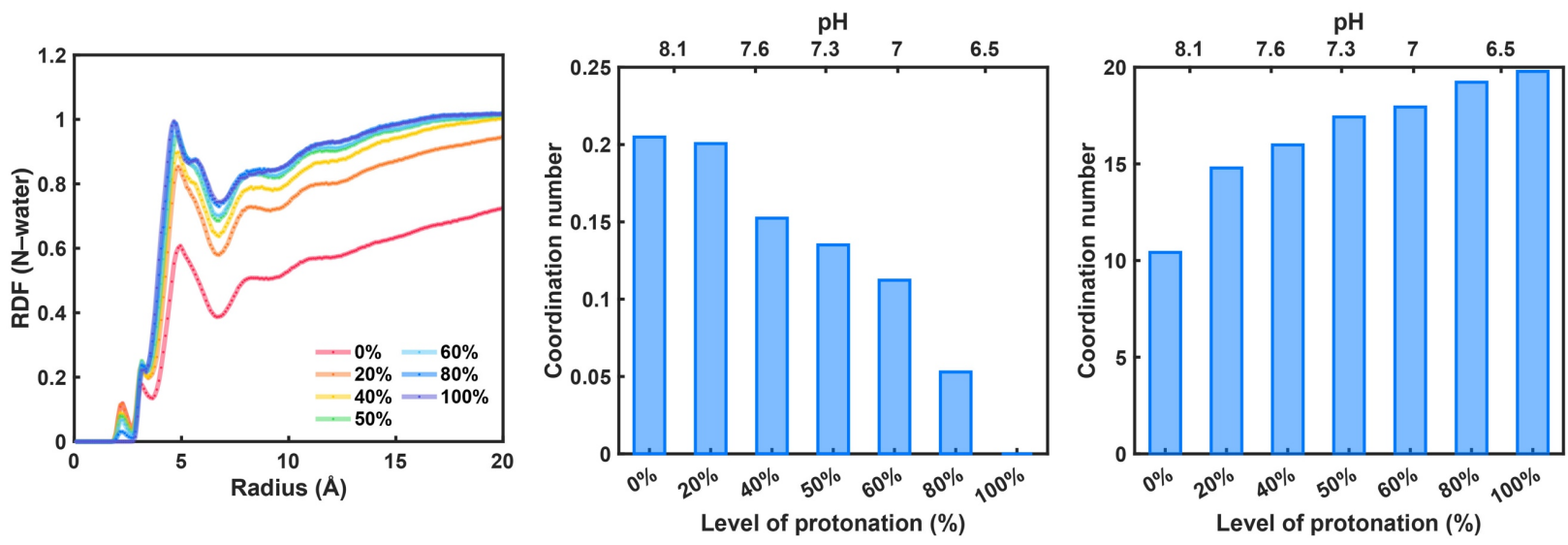

Figure S17. The radial distribution function of water at $0 \sim 100 \%$ levels of protonation, which peaks at $2.25 \AA, 3.15 \AA$ and $4.65 \AA$ (left). The coordination numbers of water molecules within $2.25 \AA$ (middle) and $4.65 \AA$ (right) relative to the nitrogen atoms on the microgel.

\section{REFERENCES}

(1) Amirav, L.; Alivisatos, A. P. Photocatalytic Hydrogen Production with Tunable Nanorod Heterostructures. J. Phys. Chem. Lett. 2010, 1, 1051-1054. 
(2) Sitt, A.; Della Sala, F.; Menagen, G.; Banin, U. Multiexciton Engineering in Seeded Core/Shell Nanorods: Transfer from Type-I to Quasi-Type-Ii Regimes. Nano Lett. 2009, 9, 3470-6.

(3) She, C.; Bryant, G. W.; Demortière, A.; Shevchenko, E. V.; Pelton, M. Controlling the Spatial Location of Photoexcited Electrons in Semiconductor Cdse/Cds Core/Shell Nanorods. Phys. Rev. $B$ 2013, 87.

(4) Wu, K.; Rodriguez-Cordoba, W. E.; Liu, Z.; Zhu, H.; Lian, T. Beyond Band Alignment: Hole Localization Driven Formation of Three Spatially Separated Long-Lived Exciton States in Cdse/Cds Nanorods. ACS Nano 2013, 7, 7173-85.

(5) Lupo, M. G.; Della Sala, F.; Carbone, L.; Zavelani-Rossi, M.; Fiore, A.; Luer, L.; Polli, D.; Cingolani, R.; Manna, L.; Lanzani, G. Ultrafast Electron-Hole Dynamics in Core/Shell Cdse/Cds Dot/Rod Nanocrystals. Nano Lett. 2008, 8, 4582-7.

(6) Muller, J.; Lupton, J. M.; Lagoudakis, P. G.; Schindler, F.; Koeppe, R.; Rogach, A. L.; Feldmann, J.; Talapin, D. V.; Weller, H. Wave Function Engineering in Elongated Semiconductor Nanocrystals with Heterogeneous Carrier Confinement. Nano Lett. 2005, 5, 2044-9.

(7) Walker, B. J.; Nair, G. P.; Marshall, L. F.; Bulovic, V.; Bawendi, M. G. Narrow-Band Absorption-Enhanced Quantum Dot/J-Aggregate Conjugates. J. Am. Chem. Soc. 2009, 131, 96245.

(8) Ferrández-Montero, A.; Quijada-Garrido, I.; Liras, M.; García, O. Thermoresponsive Random and Block Copolymers Based on Diethylene Glycol Methacrylate and a Novel Thiolated Methacrylic Monomer for the Coating of Semiconductor Nanoparticles. Eur. Polym. J. 2016, 84, 565-576.

(9) Liras, M.; Quijada-Garrido, I.; Garcia, O. Qds Decorated with Thiol-Monomer Ligands as New Multicrosslinkers for the Synthesis of Smart Luminescent Nanogels and Hydrogels. Polym. Chem. 2017, 8, 5317-5326.

(10) Yu, W. W.; Qu, L.; Guo, W.; Peng, X. Experimental Determination of the Extinction Coefficient of Cdte, Cdse, and Cds Nanocrystals. Chemistry of Materials 2003, 15, 2854-2860.

(11) Cai, Y.; Armes, S. P. A Zwitterionic Abc Triblock Copolymer That Forms a "Trinity" of Micellar Aggregates in Aqueous Solution. Macromolecules 2004, 37, 7116-7122.

(12) Wang, J.; Wolf, R. M.; Caldwell, J. W.; Kollman, P. A.; Case, D. A. Development and Testing of a General Amber Force Field. J. Comput. Chem. 2004, 25, 1157-74.

(13) Neese, F. Wiley Interdiscip. Rev.: Comput. Mol. Sci. 2012, 2, 73- 78.(B) Neese, F. ORCAAn Ab Initio, DFT and Semiempirical Program Package, Version 2017, 3.

(14) Schauperl, M.; Nerenberg, P. S.; Jang, H.; Wang, L.-P.; Bayly, C. I.; Mobley, D. L.; Gilson, M. K. Non-Bonded Force Field Model with Advanced Restrained Electrostatic Potential Charges (Resp2). Commun. Chem. 2020, 3.

(15) Lu, T.; Chen, F. Multiwfn: A Multifunctional Wavefunction Analyzer. J. Comput. Chem. 2012, 33, 580-92.

(16) Cannon, W. R.; Pettitt, B. M.; McCammon, J. A. Sulfate Anion in Water: Model Structural, Thermodynamic, and Dynamic Properties. J. Phys. Chem. 2002, 98, 6225-6230.

(17) Abraham, M. J.; Murtola, T.; Schulz, R.; Páll, S.; Smith, J. C.; Hess, B.; Lindahl, E. Gromacs: High Performance Molecular Simulations through Multi-Level Parallelism from Laptops to Supercomputers. SoftwareX 2015, 1-2, 19-25.

(18) Lemkul, J. From Proteins to Perturbed Hamiltonians: A Suite of Tutorials for the Gromacs2018 Molecular Simulation Package [Article V1.0]. Living J. Comp. Mol. Sci. 2019, 1.

(19) Darden, T.; York, D.; Pedersen, L. Particle Mesh Ewald: Ann·Log(N) Method for Ewald Sums in Large Systems. J. Chem. Phys. 1993, 98, 10089-10092. 